ISSN 0001-6012/2018/60/1/27-34 Acta Médica Costarricense, (C) 2018 Colegio de Médicos y Cirujanos de Costa Rica

\title{
Original
}

\section{Valoración de la tasa de cicatrización de una úlcera aguda en ratas Sprague-Dawley, mediante la aplicación de células madre mesenquimatosas autólogas, obtenidas del tejido adiposo}

(Healing rate assessment of an acute ulcer in Sprague-Dawley rats by applying autologous mesenchymal stem cells drawn from adipose tissue)

Fernando Zeledón-Sánchez, ${ }_{1}$ Édgar Méndez-Jiménez, ${ }^{2}$ Jessica Arroyo-Hernández, ${ }_{1}$ Silvia Castro-Piedra, ${ }_{1}^{1}$ Adriana Suárez-Urhan, ${ }^{3}$ Marco Alvarado-Aguilar, ${ }^{4}$ Orlando Morales-Matamoros ${ }^{1}$

\section{Resumen}

Objetivo: se diseñó un estudio que evaluara la tasa de cicatrización cutánea en úlceras agudas en ratas Sprague-Dawley después de recibir la administración de células madre mesenquimatosas derivadas de tejido adiposo.

Métodos: al primer grupo, denominado células madre (CM), se le administró células mesenquimatosas derivadas de tejido adiposo inyectadas, tanto periulcerosa como intraulcerosa. El segundo grupo, denominado neobol $(\mathrm{N})$, recibió tratamiento con neobol ${ }^{\mathrm{R}}$ tópico, cuyo principio activo es el clostebol. El tercer grupo, denominado control (C), fue sometido a la misma manipulación quirúrgica que los dos grupos anteriores, pero no recibió ningún tipo de tratamiento. Después de realizar una úlcera aguda en el dorso de las ratas y recibir el tratamiento respectivo, se evaluó la tasa de cicatrización (día 1 de la úlcera - día X úlcera) / día 1 de la úlcera en todos los grupos.

Resultados: se extrajo un promedio de 1,22 $\pm 0,46 \mathrm{~g}$ de muestra y se aislaron 3,5 x $10^{5}$ células, con un inóculo promedio de $2,4 \times 10^{4}$ y una viabilidad del 95,5\%. La positividad para el antígeno CD29 mediante citometría de flujo fue del 96,5\%. El análisis histológico realizado a los 7 días posteriores a la cicatrización clínica, demostró que el grupo de CM presentó la combinación de mayor vascularización y formación de epitelio, así como mayor porcentaje de cicatrización en relación con el grupo $\mathrm{N}\left(H_{(1)}=5,61 ; \mathrm{p}<0,01\right)$ y $\mathrm{C}\left(H_{(1)}=10,47 ; \mathrm{p}<0,001\right)$.

Trabajo realizado en Departamento de Fisiología Universidad de Costa Rica. Cátedra de Fisiología Universidad de Ciencias Médicas.

Afiliación de los autores: 'Cátedra de Fisiología, Universidad de Ciencias Médicas. ${ }^{2}$ Cátedra de Cirugía, Universidad de Ciencias Médicas. ${ }^{3}$ Departamento de Fisiología, Universidad de Costa Rica. ${ }^{4}$ Departamento de Bioquímica, Universidad de Costa Rica.

Fuentes de apoyo: Universidad de Ciencias Médicas y Universidad de Costa Rica.

Conflicto de interés: no hay conflictos de interés.

凶fzszeledon@gmail.com
Conclusión: el estudio sugiere que las células madre derivadas del tejido adiposo aumentan la tasa de cicatrización.

Descriptores: células madre derivadas de tejido adiposo, úlcera, cicatrización, tejido adiposo.

\section{Abstract}

Objective: To evaluate the rate of cutaneous cicatrization of acute ulcers in Sprague-Dawley rats, after receiving the administration of mesenchymal stem cells derived from adipose tissue.

Methods: There were three experimental groups. After an acute ulcer was performed in the backs of the rats they received either stem cells (SC), Clostebol, (Neobol ${ }^{\mathrm{R}}$ group, $\mathrm{N}$ ) or no treatment (control group, C), the ulcer cutaneous healing rate was assessed as follows: (ulcer day $1-$ ulcer day $\mathrm{X}$ )/in all groups day 1 . Stem cells were extracted from adipose tissue in the inguinal pad and then injected in the Stem cells group. 
Results: An average of $1.22 \pm 0,46$ grams (g) of adipose tissue was extracted and $3.5 \times 10^{5}$ cells were isolated with an average $2.4 \times 10^{4}$ inoculant, $95,5 \%$ cell viability. The CD29 antigen positivity on the stem cells assessed by flow cytometry was $96,5 \%$. The histological analysis performed 7 days after the clinical healing showed that the SC group showed the highest vascularization and epithelial tissue formation. When comparing the average healing percentage among groups, only the SC group showed significant differences in contrast with the $\mathrm{N}$ group $\left(\mathrm{H}_{(1)}=5.61 ; \mathrm{p}<0,01\right)$ and $\mathrm{C}\left(\mathrm{H}_{(1)}=\right.$ 10.47; $p<0.001)$.

Conclusion: This study suggests that mesenchymal cells derived from adipose tissue increase the healing rate.

Keywords: Adipose derived stem cells, ulcer, healing rate, adipose tissue.

Fecha recibido: 07 de julio 2017

Fecha aprobado: 16 de noviembre 2017

Las lesiones cutáneas conllevan una pérdida de la integridad de la piel y son una de las mayores causas de morbilidad a nivel mundial. ${ }^{1}$ La cicatrización de úlceras, tanto agudas como crónicas, representa un reto para el personal de salud que trata a un individuo con este padecimiento. Existen múltiples tratamientos, pero ninguno ha demostrado ser verdaderamente eficaz, por lo que muchas veces han quedado el paciente y el médico sin soluciones terapéuticas, lo cual genera enormes repercusiones socioeconómicas y biológicas a los individuos, así como a los sistemas de salud., ${ }^{2,3}$ Las células madre, debido a su pluripotencialidad y capacidad de autorrenovación, representan grandes esperanzas para la terapia de estas y otras enfermedades. ${ }^{4}$

Por otra parte, en el tejido adiposo se han descrito células madre multipotentes con la capacidad de autorrenovación, lo cual convierte a este tejido en una opción que permite extraer gran volumen de células, con una morbilidad limitada. ${ }^{5}$ Por ejemplo, en $300 \mathrm{ml}$ de lipoaspirado se pueden aislar de 2 a 3 x $10^{8}$ células madre, ${ }^{6}$ mientras que la aspiración de la médula ósea puede generar apenas de 1 × $10^{5}$ células madre. $^{4}$

El proceso de cicatrización de úlceras es complejo y requiere la integración de eventos moleculares y biológicos, tales como la migración y proliferación celular, el depósito de la matriz extracelular, la angiogénesis y el remodelado tisular. ${ }^{7}$ Se ha hipotetizado en estudios previos, que las células madre podrían contribuir a la cicatrización de úlceras y a la regeneración de piel, sin embargo, los estudios publicados al respecto aún son pocos y todavía quedan muchas preguntas sin responder., $2,7 \cdot 11$

Hasta la fecha, en los Estados Unidos la Food and Drug Administration (FDA) no ha aprobado la utilización de células madre derivadas de tejido adiposo (CMDTA) en ningún tipo de patología, en parte por la falta de estudios clínicos y preclínicos. ${ }^{12-14}$

De esta forma, el presente estudio pretende contribuir a recaudar evidencia científica que apoye o no la terapia con células madre derivadas del tejido adiposo en úlceras cutáneas, en un intento por buscar un tratamiento con mejores resultados para aliviar el dolor, angustia, incapacidad funcional, e incluso complicaciones mortales que acontecen a millones de seres humanos con estas patologías alrededor del mundo.

\section{Métodos}

\section{Animales experimentales}

El protocolo del estudio fue aprobado por el Comité Institucional de Cuidado y Uso Animal (CICUA), y los animales fueron suministrados por el Laboratorio de Ensayos Biológicos de la Universidad de Costa Rica (LEBI).

El estudio inició con una muestra de 25 ratas (14 machos y 11 hembras) Sprague-Dawley, con un peso de 241,8 $\pm 19,41$ $\mathrm{g}$, provenientes del bioterio del LEBI. Todos los sujetos de experimentación fueron sometidos a las mismas intervenciones quirúrgicas (extracción de tejido adiposo inguinal y realización de una úlcera). Posteriormente, los animales fueron distribuidos de manera aleatoria en tres grupos caracterizados por el tipo de tratamiento postoperatorio al que fueron sometidos.

El primer grupo, el cual se trató con células madre y se denominó CM, estuvo integrado por 8 animales (5 machos y 3 hembras). Se suministraron CMDTA inyectadas, tanto periulcerosa como intraulcerosa. El segundo grupo denominado $\mathrm{N}$, estuvo constituido por 9 animales ( 5 machos y 4 hembras) y recibió tratamiento con neobol ${ }^{R}$ tópico. El neobol ${ }^{R}$ se encuentra compuesto de neomicina y clostebol, siendo este último un esteroide de uso tópico que presenta mayores propiedades anabólicas que efectos androgénicos, lo cual ejerce un efecto trófico cicatrizante, induce la reepitelización, la proliferación celular y el acúmulo de matriz extracelular, por lo cual disminuiría el período de cicatrización de las lesiones cutáneas..$^{15}$ A su vez, la neomicina es un antibiótico familia de los aminoglucósidos, bactericida que inhibe la síntesis proteica bacteriana por su unión con la subunidad $30 S$ de los ribosomas. ${ }^{16}$ El tercer y último grupo utilizado como control, denominado C, estuvo integrado por 8 animales (4 machos y 4 hembras) y fue sometido a la misma manipulación quirúrgica que los dos grupos anteriores, pero no recibió ningún tipo de tratamiento 


\section{Células madres en cicatrización / Zeledón-Sánchez et al}

para la lesión, más que la escarificación, intervención que se aplicó en todos los grupos.

Todos los procedimientos fueron aprobados por el comité de cuidado animal de la Universidad de Costa Rica y estuvieron bajo normas de la ley de protección animal vigente en el país a esa fecha.

\section{Técnica quirúrgica y administración de CMDTA}

Todo el procedimiento quirúrgico fue realizado bajo anestesia general. Los animales fueron anestesiados con ketamina (90 mg por kilogramo de peso, intraperitoneal), lo que proporcionó más de 30 minutos de anestesia para realizar ambos procedimientos, la lipectomía y la úlcera. ${ }^{17}$

Para la extracción del tejido adiposo, se rasuraron ambas regiones inguinales, y luego se impregnaron con alcohol de 70 grados y yoduro de povidona al 10\%, como técnica aséptica para la disección del área mencionada. La lipectomía se efectuó 17 días antes de la realización de la úlcera y se hizo mediante la incisión de $1 \mathrm{~cm}^{2}$ en la piel inguinal, con un bisturí \#10, y la extracción del tejido adiposo mediante técnica aséptica (Figura 1).

Mediante la misma técnica aséptica se lavó y rasuró la porción dorsal sobre la cintura escapular, en donde se hizo una úlcera cutánea de aproximadamente $1 \mathrm{~cm}^{2}$ con el uso de un bisturí. Cinco minutos después de que se realizó la úlcera bajo anestesia, se inyectaron los bordes de esta (a las 12, 3, 6 y 9, según esquema del reloj) con células madre autólogas, no diferenciadas y provenientes del tejido adiposo. También se aplicaron tres inyecciones intraulcerales. El total de células madre administradas a cada rata del grupo CM fue de aproximadamente 1000 células/gramo peso ${ }^{18}$ (Cuadro 1). Al grupo $\mathrm{N}$ se le aplicó neobol ${ }^{\mathrm{R}}$ tópico y al grupo $\mathrm{C}$ no se le realizó ningún procedimiento especial. Para el dolor postoperatorio se utilizó tramadol $50 \mathrm{mg} / \mathrm{kg} /$ día subcutáneo en los tres grupos.

\section{Análisis de las úlceras}

Todos los animales de experimentación se trasladaron al bioterio en jaulas separadas. Luego, las ratas fueron removidas desde sus jaulas individuales, colocadas junto a una regla métrica (usada para la calibración y estandarización del área de la úlcera) y fotografiadas en los días postoperatorios (hasta en 14 ocasiones, dependiendo de la tasa de cicatrización de la úlcera) con una cámara digital con la misma distancia focal. Las fotografías fueron analizadas con un software especializado (Image J® National Institute of Health, Bethesda, MD, USA), para determinar la evolución del área de cicatrización de la úlcera. El porcentaje de regeneración cutánea en la úlcera fue definido mediante la siguiente fórmula: área en el día postoperatorio 1 - área en el día postoperatorio X / área en el día postoperatorio 1 x 100.,19

\section{Cuidado postoperatorio}

Se vigiló el comportamiento de los animales durante todo el postoperatorio. Después de cada medición de la úlcera, el animal fue trasladado a la jaula correspondiente, en donde pudo ingerir agua y alimento ad libitum y fue alojado bajo las condiciones ambientales necesarias y controladas para el bienestar postquirúrgico de todos los animales. ${ }^{17}$

Los animales fueron mantenidos en las condiciones normadas para esta especie, a una temperatura de $21^{\circ} \mathrm{C}$, humedad entre un 55 y 65 \% y 10 cambios de aire por hora. Los ciclos de luz fueron de 12 horas/día controlados de forma automática. Se observaron diariamente y se cambió la burucha junto a la limpieza de la jaula, cada 2 días. ${ }^{17}$

Se valoró diariamente cualquier tipo de cambio en la apariencia de los animales, hábitos en la ingesta de alimentos, agua y comportamiento que indicaran estrés en ellos. Se utilizó la escala de estrés propuesta por Wolfensohn. ${ }^{17}$

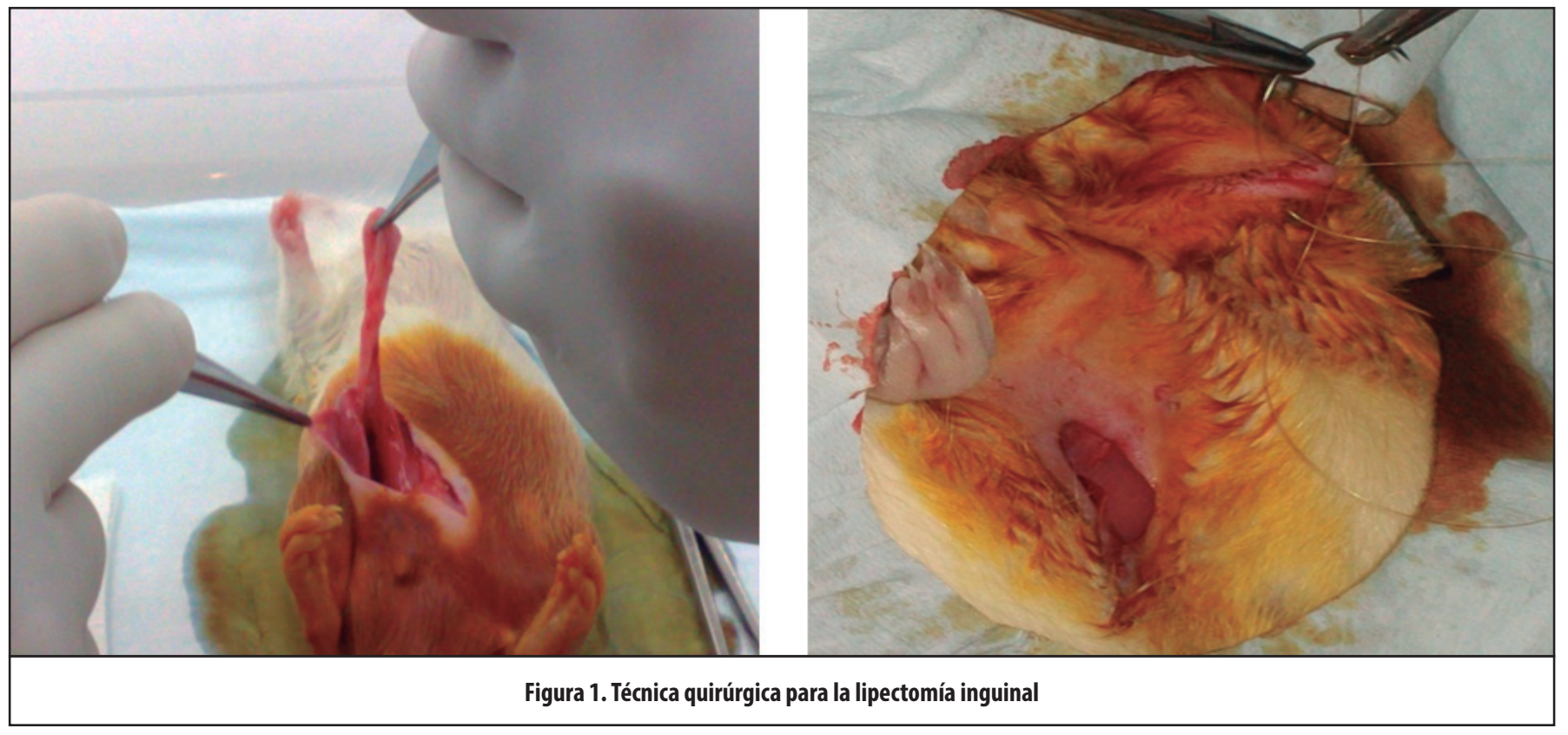




\section{Aislamiento, cultivo y marcaje de las células madre}

Se extrajo una muestra de tejido adiposo de ambas regiones inguinales de las ratas, bajo anestesia general y con técnica quirúrgica aséptica. Por gradiente de peso y por centrifugación, el tejido se dividió en un sobrenadante y una porción inferior más densa. ${ }^{20}$

Los segmentos de lipectomía de las ratas se trataron individualmente y se lavaron con una solución salina buferizada con fosfato -PBS sin $\mathrm{Ca}^{++}$ni $\mathrm{Mg}^{++}$y con antibiótico al $1 \%$ (Sigma $\left.{ }^{\circledR}\right)$, para remover los detritos contaminantes y los eritrocitos. El material finamente fragmentado se trató con la enzima colagenasa tipo I al 0,1\% (Sigma®) durante 45 a 90 minutos, a $37{ }^{\circ} \mathrm{C}$ en un agitador mecánico. La colagenasa se inactivó con un mismo volumen de medio conocido como DMEM (por sus siglas en inglés, Dulbecco`s Modified Eagle Medium) suplementado con un $10 \%$ de suero bovino fetal (SBF). Posteriormente, el homogenizado se centrifugó por $10 \mathrm{~min}$ a 1200 revoluciones por minuto y luego se filtró, para separar las partículas de acuerdo con su densidad, descartando la fase superior que contenía la grasa junto a los adipocitos diferenciados. Luego, el infranadante se resuspendió en una solución para lisis de eritrocitos compuesta de $\mathrm{NH}_{4} \mathrm{Cl} 155 \mathrm{mM} ; 10 \mathrm{mM} \mathrm{KHCO}_{3}$ y $0,1 \mathrm{mM}$ EDTA, e incubados a una temperatura ambiente por 5 minutos. Después, se volvió a centrifugar y el infranadante fue resuspendido y pasado por un filtro de 100 micrómetros. ${ }^{20,21}$

\section{Citometría de flujo}

Las células fueron analizadas mediante citometría de flujo para determinar la presencia del marcador CD29, que es una integrina de membrana y que se encuentra en las CMDTA. Además, se determinó el porcentaje de células madre que presentaban dicha proteína. Luego, las células fueron agregadas a un medio HANK'S tripsina al 0,05\% y EDTA al 0,02\%, con el fin de lograr la separación tisular. Se trataron por 30 minutos y luego se lavaron en la solución buffer del citómetro de flujo. A continuación, se incubaron por otros 30 minutos con la solución buffer del citómetro de flujo, y anticuerpos monoclonales conjugados con isocianato de flurosceína. Finalmente, las células fueron lavadas con PBS, fijadas con formaldehído al 4\% y analizadas mediante el citómetro de flujo.20,21

\section{Eutanasia y análisis histológico}

Se tomó una úlcera como cicatrizada cuando no había evidencia clínica de esta. Luego, 7 días después de la cicatrización, se sacrificó cada uno de los animales de experimentación mediante eutanasia, administrándose pentobarbital al 20\%, a una dosis de $140 \mathrm{mg} / \mathrm{kg}$ intraperitoneal. ${ }^{17}$ Las muestras de piel del dorso de las ratas donde se encontraba la úlcera fueron preparadas para el examen histológico ulterior.

Se realizó una deshidratación del especimen de piel con alcohol etílico durante un 1 minuto, luego se aclaró con tolueno y la peroxidasa endógena se neutralizó con peróxido de hidrógeno al 3\% por 10 minutos a temperatura ambiente. Siguió el proceso estándar mediante uso de un micrótomo para los cortes de piel y se agregaron en parafina fundida a $60^{\circ} \mathrm{C}$ y se colocaron en un horno, para luego dejarla solidificar a temperatura ambiente. Las secciones fueron teñidas con hematoxilina y eosina para la identificación de las capas de piel. La clasificación histológica se dividió en tres grupos: a) cambios histológicos iniciales; b) cambios histológicos intermedios y c) cambios histológicos avanzados, tal como se explicará en los resultados y la discusión (Figura 2).

Las piezas de tejido procesado se lavaron con PBS y luego se incubaron con el anticuerpo anti-BrdU en la cámara húmeda, por 16 horas, para mejorar la unión antígeno-anticuerpo y así verificar inmunohistológicamente la presencia del BrdU en el núcleo celular.

\section{Análisis estadístico}

Se clasificó la presente investigación como un estudio de tipo correlacional. Los datos fueron presentados como promedios con

\begin{tabular}{|lcccccccccc|}
\hline \multicolumn{7}{|c|}{ Cuadro 1. Datos obtenidos del aislamiento del tejido adiposo de las ratas del grupo tratado con células } \\
madre, celularidad y viabilidad celular
\end{tabular}




\section{Células madres en cicatrización / Zeledón-Sánchez et al}

sus errores estándares de la media (Media \pm EEM). Los errores superiores $(\alpha \geq 0,05)$ al nivel preestablecido se consideraron no significativos. Para contrastar la hipótesis de diferencias entre grupos se utilizó un análisis univariado de varianza (ANOVA), seguido de la prueba post hoc de la diferencia menos significativa (DMS). Cuando las variables no cumplieron con los supuestos de homogeneidad de la varianza, se utilizó el análisis no paramétrico mediante la prueba de Kruskal-Wallis $(H){ }^{22}$

\section{Resultados}

\section{Cicatrización}

Las medidas del porcentaje de cicatrización fueron realizadas hasta en catorce ocasiones después de la generación de la úlcera, con un número de medida que varió dependiendo de la tasa de cicatrización de cada animal. Fueron comparados los sujetos experimentales de los tres grupos: CM, C y N. Entre las medidas 1 y 5 no se presentaron diferencias significativas. En la medida 6 se presentó una cicatrización más acelerada y significativamente superior por parte del Grupo CM, en comparación con el C $\left(H_{(1)=} 5,22 ; \mathrm{p}<0,02\right)$ y $\mathrm{N}\left(H_{(1)=} 4,91 ; \mathrm{p}\right.$ $<0,02)$. Para las medidas de los días 7 y 8 , solo se presentaron diferencias estadísticamente significativas con el grupo $\mathrm{C}$ $\left[\left(H_{(1)=} 9,24 ; \mathrm{p}<0,02\right) ;\left(H_{(1)} 3,81 ; \mathrm{p}<0,05\right)\right.$, respectivamente] pero no con el grupo N. Este último no presentó diferencias significativas con el C.

A partir de la medida 9 y hasta la 14 no se presentaron diferencias significativas en cuanto al porcentaje de cicatrización entre ninguno de los grupos. Aun así, al comparar el porcentaje promedio de cicatrización entre los grupos se evidenciaron diferencias significativamente superiores por parte del grupo $\mathrm{CM}$ en relación con el grupo $\mathrm{N}\left(H_{(1)=} 5,61 ; \mathrm{p}<0,01\right)$ y $\mathrm{C}$ $\left(H_{(1)=} 10,47 ; \mathrm{p}<0,001\right)$, no habiéndose presentado diferencias entre estos dos últimos $\left(H_{(1)=} 1,13 ; \mathrm{p}<0,28\right)$ (Figura 3).

\section{Peso de los animales}

Debido a que el peso de los animales es un signo de estrés ${ }^{17} y$ puede repercutir en la tasa de cicatrización, estos fueron pesados en tres momentos. El primer evento de pesaje se produjo cuando se extrajo el tejido adiposo; el segundo se realizó cuando se les practicó la úlcera a los sujetos de experimentación, y el tercer pesaje, al momento de la eutanasia (entre 8 y 14 días después de hecha la úlcera). Los valores correspondientes al peso de los animales se distribuyeron de manera homogénea [Levene ${ }_{(2,73)}=$ $1,90 ; p=0,15]$ y se presentó un comportamiento creciente acorde a lo esperado. Los tres momentos de pesado difirieron de forma significativa entre los grupos $\left[\mathrm{F}_{(2,58)}=126,29 ; \mathrm{p}<0,0001\right]$. La comparación entre los promedios totales evidenció pesos significativamente inferiores en los animales del grupo CM en comparación con el grupo N (DMS; $p<0,04)$, no así con el C (DMS; $p<0,14)$. No se presentaron diferencias significativas entre estos dos últimos (DMS; $p<0,58$ ).

\section{Aislamiento y cultivo del tejido adiposo (grupo células madre)}

Los resultados alcanzados a partir de los promedios de los valores presentados en el Cuadro 1, reflejan que el peso promedio de los animales, previo a la extracción del tejido adiposo, fue de $242 \mathrm{~g}$, con una recolección promedio de 1,22 g de muestra y un total de $9,79 \mathrm{~g}$ a partir de 8 ratas. Se aislaron $3,5 \times 10^{5}$ células con un inóculo promedio de 2,4 x 104; una viabilidad del $95,5 \%$ y una mortalidad del cultivo del $4,43 \%$. Los cultivos celulares no presentaron contaminación.

Además, no hubo diferencias estadísticamente significativas entre hembras y machos en cuanto al peso corporal $\left(H_{(1)} 2,90\right.$; $\mathrm{p}<0,08)$, el peso de la muestra de tejido adiposo $\left(H_{(1)=} 0,73 ; \mathrm{p}\right.$ $<0,39)$, y la proporción del peso de la muestra en función del peso corporal $\left(H_{(1)=} 0,01 ; p<0,91\right)$. Asimismo, la proporción de células madre en función del peso de la muestra extraída, tampoco se diferenció significativamente entre sexos $\left(H_{(1)=} 2,27\right.$; $\mathrm{p}<1,36)$.

\section{Células madre}

La citometría de flujo es una herramienta que permite identificar la expresión de proteínas de membrana en distintas células, y en este caso, poder asegurar la presencia de células madre en los cultivos, ya que por su simple morfología, estas células podrían coincidir con otro tipo celular (por ejemplo,

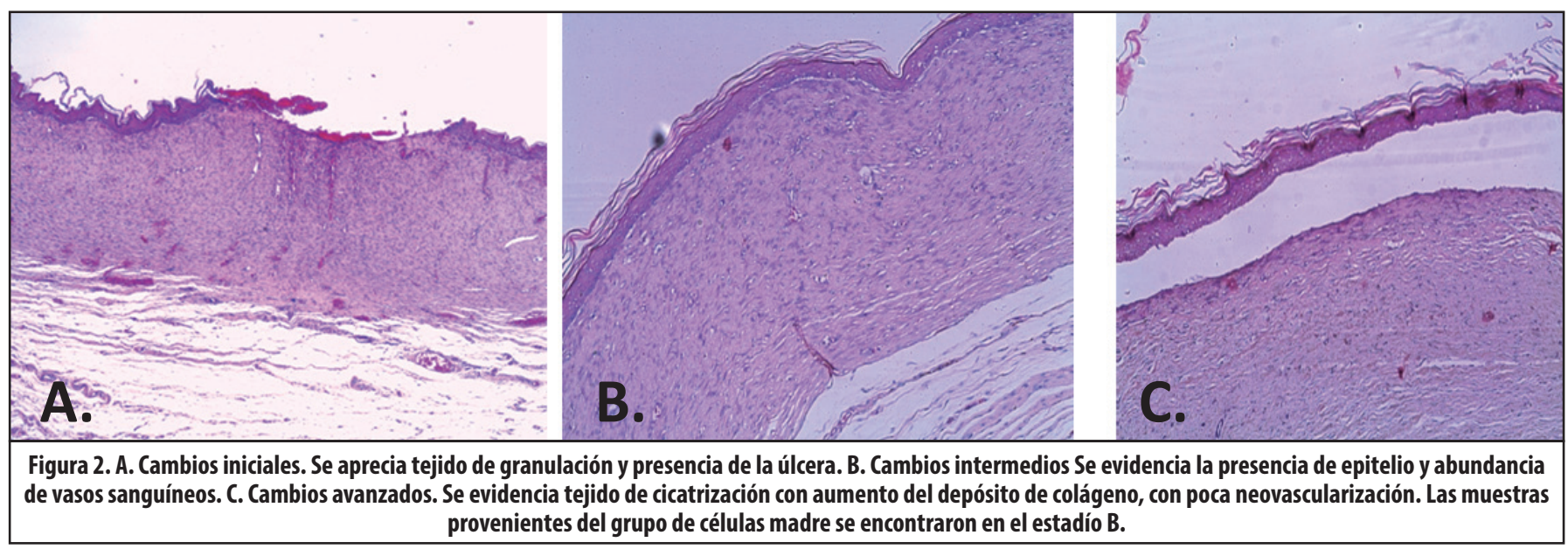


fibroblastos). Mediante citometría de flujo se pudo identificar la presencia del CD29 en las CMDTA del grupo CM; el promedio de positividad para el CD29 fue de un 96,58\%.

El análisis histológico reveló la presencia de tres condiciones distintas de cicatrización. Estas fueron clasificadas de la siguiente forma: 1) Cambios iniciales: cuando aún había evidencia de úlcera desde el punto de vista histológico; 2) Cambios intermedios: cuando se encontraba la presencia tejido vascularizado y epitelio y 3) Cambios avanzados: cuando había tejido conectivo, epitelio, muy poca vascularización (Figura 2).

Se presentaron diferencias estadísticamente significativas $\left(H_{(2)=} 7,15 ; \mathrm{p}<0,02\right)$ entre los animales del grupo células madre y los otros dos grupos, en cuanto a la cicatrización presentada producto de la histología, evidenciando una predominancia en cambios intermedios.

\section{Discusión}

El proceso de cicatrización requiere interacciones entre las células de la dermis, epidermis, y la secreción de factores provenientes de células inflamatorias, fibroblastos y queratinocitos. $^{7}$

Uno de los principales hallazgos evidenciados por el estudio fue que el grupo tratado con CMDTA presentó una tasa de cicatrización más rápida que los otros dos, siendo esta diferencia estadísticamente significativa $(p<0,05)$. Dicho fenómeno también ha sido reportado por otros autores. ${ }^{7,18,19,23}$

Se ha hipotetizado que las células madre podrían contribuir a la cicatrización de úlceras mediante mecanismos directos e indirectos ${ }^{7,24,22,25}$ En teoría, el uso de células madre en úlceras cutáneas presentaría ventajas sobre la administración de un único agente terapéutico, debido a que las células madre podrían interactuar con el microambiente y modular la actividad de otras células a través de la secreción de múltiples factores y citoquinas (mecanismos indirectos). ${ }^{1,18}$ Además, estudios han demostrado que las células madre mesenquimatosas se pueden transdiferenciar hacia queratinocitos, células endoteliales, fibroblastos y pericitos (mecanismos directos); las cuales también secretan factores inmunomoduladores, aumentan la matriz extracelular y contribuyen al soporte de la úlcera y a la regulación de la respuesta inmunológica en dichas lesiones. ${ }^{18,20,26,27,28}$ Aunque en el estudio no se buscó identificar los factores secretados por células madre, ya sea exógenas o endógenas, las células madre administradas se marcaron con BrdU, en un intento de analizar hacia qué estirpe histológica se transdiferenciarían dichas células. Sin embargo, no se logró identificar mediante inmunohistoquímica, rastros del BrdU.

Dentro de posibles explicaciones, es conocido que las células aumentan su tasa de replicación en situaciones en donde hay estrés celular, como en una úlcera aguda. De esta forma, debido a que el BrdU es un marcador nuclear y a que desde la inyección subcutánea hasta la eutanasia transcurrieron en promedio 28 días en el grupo CM, es probable que la "dilución" del marcador por división nuclear haya imposibilitado la identificación de este. Por lo tanto, en este trabajo no se pudo afirmar (pero tampoco descartar) que hubiera diferenciación de células madre hacia determinadas estirpes celulares. Por otra parte, debido al ambiente hostil que las úlceras presentan (hipoxia, respuesta inflamatoria, factores proapoptóticos) para el implante de células madre, algunos autores sostienen que la mayor contribución de estas es su efecto paracrino, al secretar diversas sustancias que promueven que las células madre residentes y otras células fomenten la cicatrización. ${ }^{18,24}$

Uno de los principales mecanismos atribuido a las CMDTA y su beneficio en la cicatrización, es su facilidad para contribuir a dos procesos independientes: la vasculogénesis y la angiogénesis. El primero es la capacidad de promover la formación de nuevos vasos sanguíneos a partir de células progenitoras endoteliales; el segundo, la génesis de nuevos vasos sanguíneos a partir de los capilares existentes. ${ }^{1}$ Lee et al., demostraron que las CMDTA, bajo estímulos hipóxicos (tales como los que se presentan en una úlcera) son capaces de secretar factores angiogénicos (como por ejemplo el factor de crecimiento endotelial y vascular (Vascular Endothelial Growth Factor, VEGF) y el factor de crecimiento de fibroblastos básico (Basic Fibroblast Growth Factor, BFGF), entre otros) y aumentar la formación de nuevos vasos sanguíneos, incrementando el aporte sanguíneo, la constitución de tejido de granulación y las tasas de reepitelización. ${ }^{29}$ En el estudio se analizaron las muestras histológicas de las zonas en donde estaban las úlceras 7 días posteriores a la evidencia de la cicatrización clínica. El patólogo que analizó dichas láminas se encontraba a ciegas al no conocer la procedencia de las muestras. Se hallaron tres estadios histológicos. En el primero, llamado "cambios iniciales", todavía se evidenciaba muestras de ulceración y tejido de granulación. En el segundo grupo, denominado "cambios intermedios", se observó epitelio, pero gran vascularización, y en el tercer grupo, llamado "cambios avanzados", se encontró más tejido colágeno, epitelio y poca vascularización.

Fue llamativo como las muestras provenientes del grupo de CM clasificaron dentro del grupo de cambios intermedios, el cual presentaba, como se mencionó, mayor vascularización y epitelio reciente. Diversos autores han documentado la capacidad de las CMDTA de diferenciarse de las células

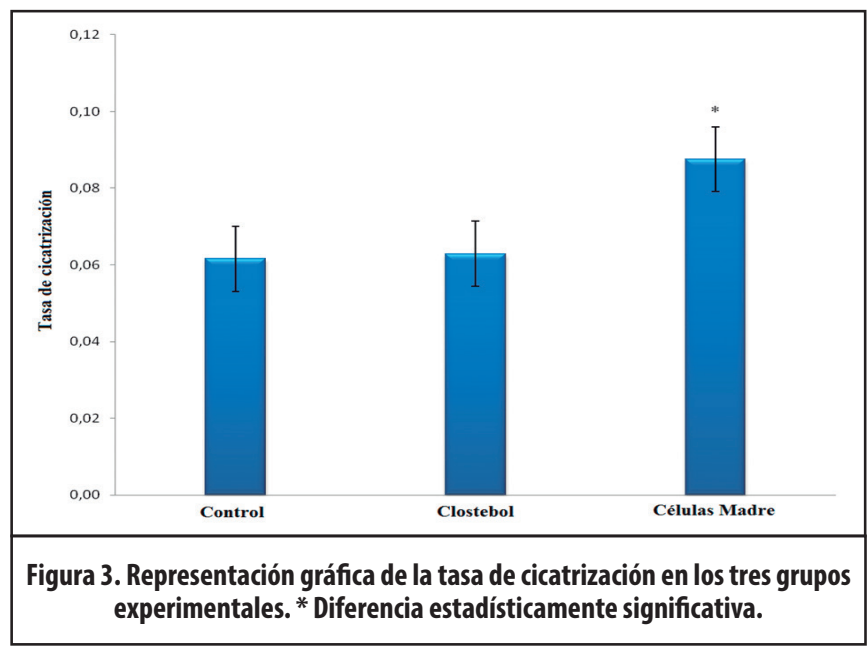




\section{Células madres en cicatrización / Zeledón-Sánchez et al}

endoteliales..$^{27,30,31}$ Planat-Benard et al. observaron que células madre cultivadas expresaban la proteína CD31, además de que las células fueron capaces de formar redes de vasos sanguíneos, consistentes con la formación de estructuras vasculares. ${ }^{31}$ En otro estudio, ratas con una extremidad isquémica a las cuales se les administró CMDTA, mejoraron la irrigación de dicha extremidad y se documentó procesos de angiogénesis, lo que confirma la gran facilidad de las células madre mesenquimatosas para formar vasos sanguíneos. ${ }^{32}$

El peso promedio de los animales fue menor en el grupo de $\mathrm{CM}$, lo que se puede explicar porque los sujetos de este grupo cicatrizaron más rápido, con un tiempo menor para la eutanasia. La tasa de ganancia de peso en el grupo de CM fue de 4,46 g, encontrándose dentro lo estipulado en la bibliografía. ${ }^{17}$ Por 10 tanto, los animales presentaron una ganancia de peso adecuada y esto no repercutió en las tasas de cicatrización.

El estudio permite concluir que la aplicación local de células madre de tejido adiposo, aumenta la tasa de cicatrización en úlceras agudas. Dentro de este ámbito, el tejido adiposo pareciera aventajar a otras fuentes de células madre, ya que no solo abunda en el cuerpo humano, sino que es relativamente fácil de recolectar en grandes cantidades y extraer células madre de este. Además, las CMDTA presentan gran potencial para promover la formación de vasos sanguíneos, fenómeno crucial en la reparación de cualquier tejido lesionado. Por supuesto, estos hallazgos podrían beneficiar a pacientes con múltiples problemas cutáneos, tales como: quemaduras, úlceras isquémicas, úlceras diabéticas, úlceras por compresión o por estasis venosa, entre otras.

Aunque las úlceras crónicas son las que presentan mayor morbilidad y el estudio se realizó en un modelo de úlceras agudas, en las cuales el microambiente es distinto, el hecho de que en la presente investigación el grupo de células madre cicatrizara primero, abre las puertas para futuros ensayos clínicos con el uso de células madre en el tratamiento de úlceras crónicas.

Se necesitan más estudios para contestar múltiples preguntas que aún no tienen respuestas satisfactorias: ¿Cuál es la dosis óptima de células madre que se deben administrar?, ¿Es necesario administrar dosis repetidas y a qué intervalos?, ¿Deben acompañarse de factores de crecimiento?, ¿Cuáles son los efectos adversos de dicha terapéutica?, ¿Será mejor el tratamiento inyectado, tópico o endovenoso?, entre otras. ${ }^{8,9,10,33}$

Agradecimientos: debemos dar las gracias a la Dras. Abigail Porras y Priscilla Orlich, por su colaboración en los procedimientos de citometría de flujo; al Dr. Luis Zamora, por el análisis histopatológico de las úlceras, y a las Dras. Cecilia Díaz y Silvia Quesada, por el apoyo en la logística del proyecto.

\section{Referencias}

1. Ko SH, Nauta A, Wong V, Glotzbach J, Gurtner GC, Longaker MT. The Role of Stem Cells in Cutaneos Wound Healing: What Do We Really Know? Plast. Reconstr. Surg. 2011;127 (Suppl.): 10S.
2. Cherubino M, Rubin JP, Miljkovic N, Kelmendi-Doko A, Marra KG. AdiposeDerived Stem Cells for Wound Healing Applications. Ann Plast Surg. 2011;66:210-215.

3. Hanson, SE, Bentz ML, Hematti P. Mesenchymal Stem Cell Therapy for Nonhealing Cutaneous Wounds. Plast. Reconstr. Surg. 2010;125:510.

4. Torres FC, Rodrigues CJ, Stocchero IN, Ferreira MC. Stem Cells from the fat tissue of Rabbits: An easy-to find Experimental Source. Aesth Plast Surg. 2007;31:574-578.

5. Fraser, JK, Schreiber R, Strem B, Zhu M, Alfonso Z, Wulur I, et al. Plasticity of human adipose stem cells toward endothelial cells and cardiomyocites. Nature. 2006;3:33-37.

6. Zuk PA, Zhu M, Ashjian P, De Ugarte DA, Huang JI, Mizuno H, Alfonso ZC, et al. Human Adipose Tissue is a Source of Multipotent Stem Cells. Mol Biol Cell. 2002; 13:4279-4295.

7. Lim JS, Yoo G. Effects of Adipose-derived stromal cells and of their Extract on Wound Healing in a Mouse Model. J Korean Med Sci. 2010;25:746-751.

8. Bertozzi N, Simonacci F, Grieco MP, Grignaffini E, Raposio E. The biological and clinical basis for the use of adipose-derived stem cells in the field of wound healing. Ann Med Surg. 2017;20:41e - 48.

9. Na YK, Ban JJ, Lee M, Im W, Kim M. Wound healing potential of adipose tissue stem cell extract. Biochem Biophys Res Commun. 2017;485:30e-34.

10. Marfia G, Navone SE, Di Vito C, Ughi N, Tabano S, Miozzo M, et al Mesenchymal stem cells: potential for therapy and treatment of chronic nonhealing skin wounds. Organogenesis. 2015;11:183-206.

11. Hur W, Lee HY, Min HS, Wufuer M, Lee CW, Hur JA, et al. Regeneration of full-thickness skin defects by differentiated adipose-derived stem cells into fibroblast-like cells by fibroblast- conditioned medium. Stem Cell ResTher. 2017;8:92.

12. Witten CM, McFarland RD, Simek SL. Concise Review: The U.S Food and Drug Administration and Regenerative Medicine. Stem Cells Transl Med. 2015;4:1495-1499.

13. Turner L. US stem cell clinics, patient safety, and the FDA. Trends Mol Med. 2015; 21:271-273.

14. Sipp D, Turner L. U.S. Regulation of Stem Cells as Medical Products. Science. 2012; 338:1296-1297

15. Maccaroni E, Mele A, Del Rosso R, Malpazzi L. Clostebol acetate. Acta Cryst. 2011; E67:01952-01953.

16. MacDonald RH, Beck M. Neomycin: a review with particular reference to dermatological usage. Clin Exp Dermatol. 1983;8:249-258.

17. Wolfensohn S, Lloyd M. Handbook of laboratory animal management and welfare, Third Edition. Oxford: Blackwell Publishing, 2003.

18. Kim WS, Park BS, Sung JH, Yang JM, Parks SB, Kwak SJ, et al. Wound healing effect of adipose-derived stem cells: a critical role of secretory factors on human dermal fibroblasts. J Dermatol Sci. 2007;48:15-24.

19. Altman AM, Matthias N, Yan Y, Song YH, Bai X, Chiu ES, et al. Dermal matrix as a carrier for in vivo delivery of human adipose-derived stem cells. Biomaterials. 2008; 29:1431-1442.

20. Zuk PA, Zhu M, Mizuno H, Huang J, Futrell JW, Katz AJ, et al. Multilineage cells from human adipose tissue: implications for cell-based therapies. Tissue Eng. 2001; 7:211-28.

21. Yoshimura K, Shigeura T, Matsumoto D, Sato T, Takaki Y, Aiba-Kojima, et al. Characterization of freshly isolated and cultured cells derived from the fatty and fluid portions of liposuction aspirates. J Cell Physiol. 2006;208:64-76.

22. Worthy G. Statistical analysis and reporting: common errors found during peer review and how to avoid them. Swiss Med Wkly. 2015;145:w14076.

23. Wu Y, Chen L, Scott PG, Tredget EE. Mesenchymal stem cells enhance wound healing through differentiation and angiogenesis. Stem Cells. 2007;25:264859.

24. Badillo AT, Redden RA, Zhang L, Doolin EJ, Liechty KW. Treatment of diabetic wounds with fetal murine mesenchymal stromal cells enhances wound closure. Cell Tissue Res. 2007;329:301-311.

25. Lau K, Paus R, Tiede S, Day P, Bayal A, et al. Exploring the role of stem cells in cutaneous wound healing. Exp Dermatol. 2009;18:921-933. 
26. Chen L, Tredget EE, Wu PY, Wu Y. Paracrine factors of mesenchymal stem cells recruit macrophages and endothelial lineage cells and enhance wound healing. PLoS One. 2008;3:e1886.

27. Gimble JM, Katz AJ, Bunnell BA. Adipose-Derived Stem Cells for Regenerative Medicine. Cir Res. 2007;100:1249-1260.

28. Stoff A, Rivera AA, Sanjib Banerjee N, Moore ST, Michael Numnum T, Espinosa-de-Los-Monteros A et al. Promotion of incisional wound repair by human mesenchymal stem cell transplantation. Exp Dermatol. 2009;18:362 369.

29. Lee EY, Xia Y, Kim WS, Kim MH, Kim TH, Kim KJ, et al. Hypoxia-enhanced wound healing function of adipose-derived stem cells: Increase in stem cell proliferation and up-regulation of VEGF and Bfgf. Wound Repair Regen. 2009; 17:540-547.
30. Cao Y, Sun Z, Liao L, Meng Y, Han Q, Zhao RC. Human adipose tissue-derived stem cells differentiate into endotelial cells in vitro and improve postnatal neovascularitation in vivo. Biochem Biophys Res Commun. 2005;332:370 379 .

31. Planat-Benard V, Silvestre JS, Cousin B, André M, Nibbelink M, Tamara R, et al. Plasticity of human adipose lineage cells toward endothelial cells: physiological and therapeutic perspectives. Circulation. 2004;109:656-663.

32. Moon MH, Kim SY, Kim YJ, Kim SJ, Lee JB, Bae YC, et al. Human adipose tissue-derived mesenchymal stem cells improve postnatal neovascularization in a mouse model of hindlimb ischemia. Cell Physiol Biochem. 2006;17:279-290.

33. Fu X, Li H. Mesenchymal stem cells and skin wound repair and regeneration: possibilities and questions. Cell Tissue Res. 2009;335:317-321. 